\title{
Life Cycle Gap Analysis for Product Circularity and Sustainability-a Case Study with Three Different Products
}

\author{
Michael Dieterle ${ }^{1}$ (1) $\cdot$ Tobias Viere $^{2}$
}

Received: 27 October 2021 / Revised: 2 February 2022 / Accepted: 3 February 2022 / Published online: 3 March 2022

(c) The Author(s) 2022

\begin{abstract}
This paper aims to demonstrate the applicability and benefits of life cycle gap analyses for systematically integrating circular economy considerations into life cycle assessment. It presents life cycle gap analyses for three entirely different products (rechargeable batteries, T-shirts, plastic bottles), compares the applications and results, and draws conclusions on the usefulness of the method.

The case studies reveal life cycle gaps of 54\% (plastic bottles), $61 \%$ (rechargeable batteries), and 98\% (T-shirts), indicating high potential for further circularity improvements in the current life cycle systems of different industries and product groups. At the same time, a potential weakness of the method is underlined. Even considering options to increase circularity, life cycle gaps of at least $45 \%$ still exist, raising the question of what measures are really needed in order to achieve product circularity and sustainability. The analysis demonstrates the general applicability of life cycle gap analyses and their contribution to the integration of circular decision-making and life cycle thinking.
\end{abstract}

Keywords Life cycle assessment $\cdot$ Life cycle interpretation · Circular economy $\cdot$ Recycling $\cdot$ Life cycle gap analysis · Product environmental footprint

\section{Introduction}

Sustainable development requires the closure of product material and energy cycles, and significant reductions in environmental impacts across the entire life cycle. (UN 2015) Quantitative approaches, such as life cycle assessment (LCA), allow the environmental impacts to be analyzed and assessed based on their material and energy cycles from cradle to grave, or from cradle to second life. Hence, such comprehensive LCA studies contain not only all the relevant information to assess products' life cycle impacts, but also to evaluate their circularity. In order to highlight this mindset, a life cycle gap analysis (LCGA; Dieterle et al. 2018) was developed as a specific technique to interpret LCA results with emphasis on circular economy (CE) principles, which

Michael Dieterle

michael.dieterle@ict.fraunhofer.de

1 Fraunhofer Institute for Chemical Technology ICT, Joseph-von-Fraunhofer-Straße 7, 76327 Pfinztal, Germany

2 Institute for Industrial Ecology - INEC, Pforzheim University, Tiefenbronner Straße 65, 75175 Pforzheim, Germany aim at closing products' material loops and thereby minimizing resource inputs, waste, emissions, and energy leakages (Geissdoerfer et al. 2017). This paper aims to demonstrate the applicability and benefits of the LCGA method for systematically integrating CE considerations into LCA.

The basic idea of LCGA is to identify a product's life cycle gap (LCG) which results from the difference between the environmental impacts of the product's initial manufacturing and its environmental credits after recycling. In contrast to the common assessment and interpretation of LCA studies, environmental credits in the end-of-life (EoL) phase are uncoupled from environmental impacts for recycling and compared to initial impacts of the manufacturing phase. In this way, circular economy thinking is given its own stage within life cycle assessment interpretation.

Figure 1 illustrates the iterative procedure of the LCGA, following the six defined steps of the methodology (Dieterle et al. 2018).

To exemplify and validate the applicability of the LCGA methodology, this study assesses three different types of products. Based on their respective EU product environmental footprint (PEF) pilot LCA studies, it examines a rechargeable nickel-metal hydride (Ni-MH) battery, a T-shirt, and a 
Fig. 1 Iterative procedure of the LCGA according to Dieterle et al. (2018)

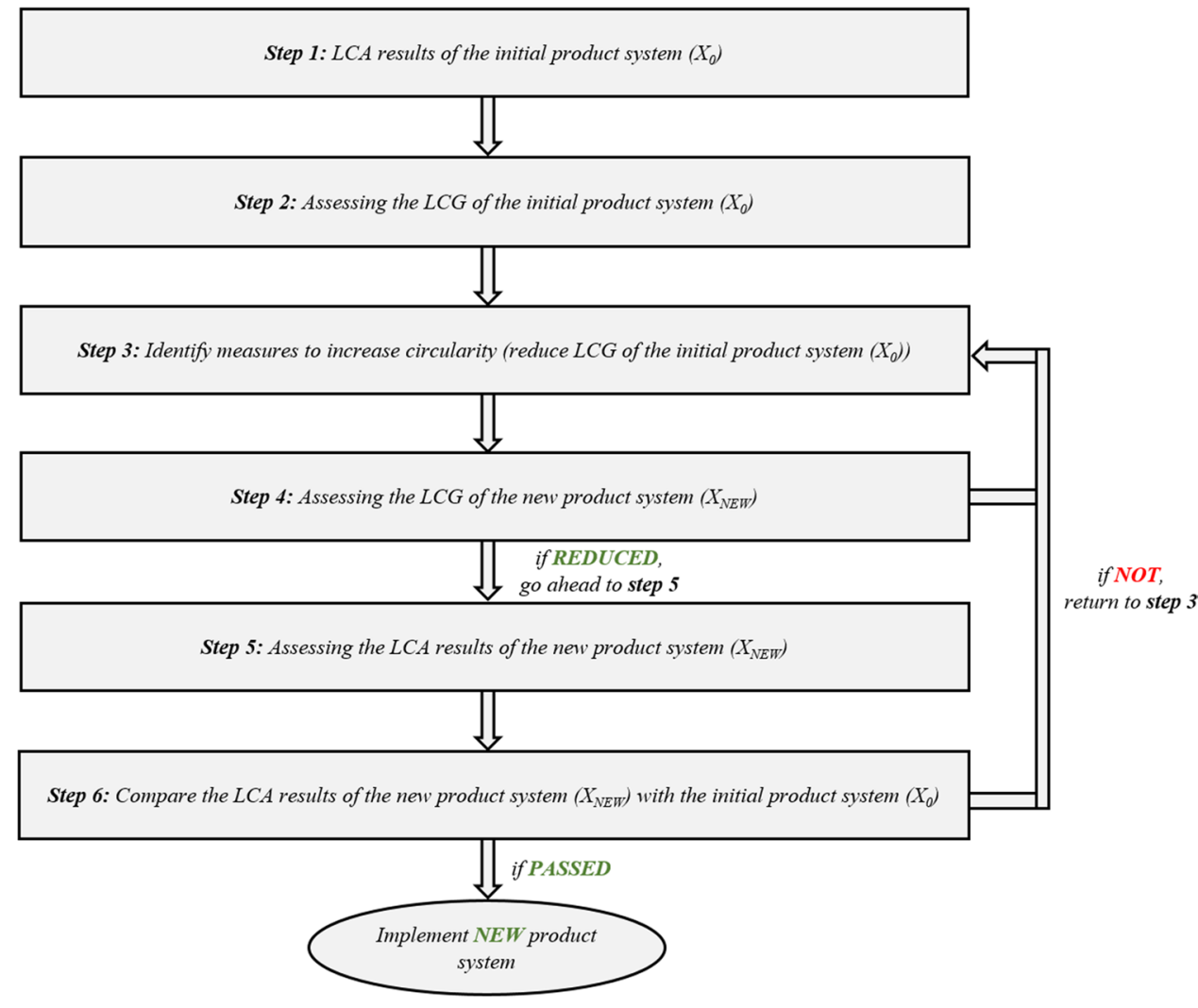

one-way polyethylene terephthalate (PET) bottle. The three products' LCGA implementation and results are compared and discussed with regard to applicability, benefits, and limitations of the method in general.

\section{LCGA Application}

LCGA was applied to a rechargeable Ni-MH battery, a T-shirt, and a one-way PET bottle. These common products were selected to represent a large range of products with different complexities, raw materials, and applications. Data for the status quo of these products have been derived from PEF pilot studies (EC 2018a, b; EC 2019). The publicly available studies provide a huge level of detail and transparency, are based on the work of LCA experts from the respective industries, and follow comprehensive LCA guidelines. The functional unit (FU) of the different products is defined as follows:

- Ni-MH battery- " $1 \mathrm{kWh}$ of the total energy provided over the service life by the battery system" (EC 2018a);

- One-way PET bottle $1.5 \mathrm{l}$ - " to provide $100 \mathrm{ml}$ of water" (EC 2018b);

- T-shirt-“"to wear a clean T-shirt until it becomes dirty 52 times" (EC 2019).
The whole life cycle of the three products is taken into account and divided into the phases of raw material acquisition, production of the main product, use phase (including product distribution), and EoL. While the product environmental footprint pilot studies feature a range of environmental impact categories, this paper focuses on climate change (global warming potential-GWP 100) only, expressed in grams of carbon dioxide equivalent $\left(\mathrm{gCO}_{2} \mathrm{eq}\right)$. Climate change is of highest concern and the best known and most robust environmental impact category, and is used as a proxy for all environmental impacts here. In principle, the LCGA method is capable of including several different environmental impact categories while using single-score indicators, such as Eco-Points (see, for example, Ahbe et al. (2018); Sala et al. (2018); Zampori and Pant (2019)).

Step 1: LCA Results of the Three Representative Products. According to the first step of the methodology (see Fig. 1), Table 1 summarizes the LCA results of the three representative products derived from product environmental footprint pilot studies (EC 2018a, b; EC 2019).

With a share of more than $70 \%$, the manufacturing phase (raw material acquistion and production) dominates the life cycle impacts of all products. The use phase has a share of between 15\% (battery) and 29\% (T-shirt). With a higher contribution of renewable energy sources to the overall energy 
Table 1 LCA results of the three representative products' in grams of carbon dioxide equivalents $\left(\mathrm{gCO}_{2} \mathrm{eq}\right)$ during one life cycle according to the defined functional unit

\begin{tabular}{|c|c|c|c|c|c|c|}
\hline \multirow{2}{*}{ Life cycle phases } & \multicolumn{2}{|c|}{ One-way PET bottle } & \multicolumn{2}{|c|}{ Ni-MH battery } & \multicolumn{2}{|l|}{$T$-shirt } \\
\hline & absolute $\left(\mathrm{gCO}_{2} e q\right)$ & relative (\%) & absolute $\left(\mathrm{gCO}_{2}\right.$ eq) & relative (\%) & absolute $\left(\mathrm{gCO}_{2}\right.$ eq) & relative (\%) \\
\hline Raw material acquisition & 8.3 & $56 \%$ & 1,155 & $81 \%$ & 1,900 & $31 \%$ \\
\hline Production & 3.3 & $22 \%$ & 55 & $4 \%$ & 2,500 & $40 \%$ \\
\hline Subtotal Manufacturing & 11.6 & $78 \%$ & 1,210 & $85 \%$ & 4,400 & $71 \%$ \\
\hline Use & 3.3 & $22 \%$ & 220 & $15 \%$ & 1,800 & $29 \%$ \\
\hline Total $_{\text {cluse }}$ & 14.9 & $100 \%$ & 1,430 & $100 \%$ & 6,200 & $100 \%$ \\
\hline Recycling & 3.1 & $21 \%$ & 74 & $5 \%$ & 200 & $3 \%$ \\
\hline Credits & -5.3 & $-36 \%$ & -478 & $-33 \%$ & -100 & $-2 \%$ \\
\hline Subtotal End-of-Life & -2.2 & $-15 \%$ & -404 & $-28 \%$ & 100 & $2 \%$ \\
\hline Total $_{0}$ & 12.7 & $85 \%$ & 1,026 & $72 \%$ & 6,300 & $102 \%$ \\
\hline
\end{tabular}

mix in the future, in the long run, the importance of the use phase is likely to diminish further for all three products.

Results within EoL (sum of environmental impacts for recycling minus environmental credits for recovery of energy and materials) indicate positive effects of EoL treatment for the battery and the PET bottle and almost no effect for the T-shirt.

Step 2: Assessing the LCG of the Initial Product System. The LCG is computed by deducting EoL credits from the manufacturing impacts (LCA results see Table 1):

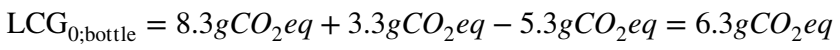

$\mathrm{LCG}_{0 ; \text { battery }}=1,155 \mathrm{gCO}_{2} e q+55 \mathrm{gCO}_{2} e q-478 g \mathrm{CO}_{2} e q=732 \mathrm{gCO}_{2} e q$

$\mathrm{LCG}_{0 \text {;shirt }}=1,900 g \mathrm{CO}_{2} e q+2,500 g \mathrm{CO}_{2} e q-100 \mathrm{gCO}_{2} e q=4,300 g \mathrm{CO}_{2} e q$

Figure 2 illustrates the life cycle gaps of the three products: (a) PET bottle, (b) NiMH-battery, (c) T-shirt.

The results for the PET bottle show that, despite an effective recycling rate of $63 \%$ after mechanical treatment and regranulation (calculated from EC 2018b), there is still a life cycle gap of at least $54 \%$. This is due to losses of $26 \%$ for the recovery of secondary PET material and energy $\left(8.3 \mathrm{gCO}_{2} \mathrm{eq}=72 \%\right.$ for $\mathrm{RMA} ;-41 \%$ for recovery of secondary PET material; $-5 \%$ for energy recovery), but also due to losing the value added in bottle production $\left(3.3 \mathrm{gCO}_{2} \mathrm{eq}=28 \%\right)$.

The Ni-MH battery obtains similar results (see Fig. 2b). In the EoL phase, a mechanical pre-treatment followed by a pyrometallurgical and hydrometallurgical recycling of the battery allows the recovery of certain elements and metals at high qualities and quantities. For steel, an effective recycling rate over $90 \%$, and for nickel sulfate and cobalt sulfate a rate of over $50 \%$ compared to virgin material can be achieved (calculated from EC 2018a). Overall, though, a LCG of $61 \%$ remains and indicates a high potential for further improvement from a CE perspective.

The results for the T-shirt (see Fig. 2c) reveal the largest LCG of around $98 \%$ and indicate a significant potential for further improvement from a CE perspective. According to the state of the art (EC 2019), only 11\% of the cotton fibres are recycled (downcycled) into wiping cloths and insulation

Relative environmental impacts (\%) from a circular economy perspective based on grams of carbon dioxide equivalents $\left(\mathrm{gCO}_{2} \mathrm{eq} /\right.$ functional unit)

(a)

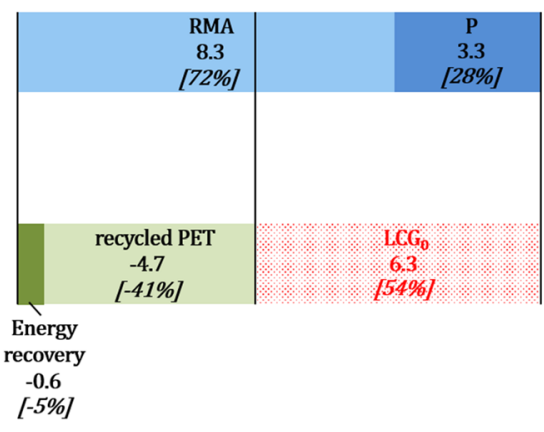

(b)

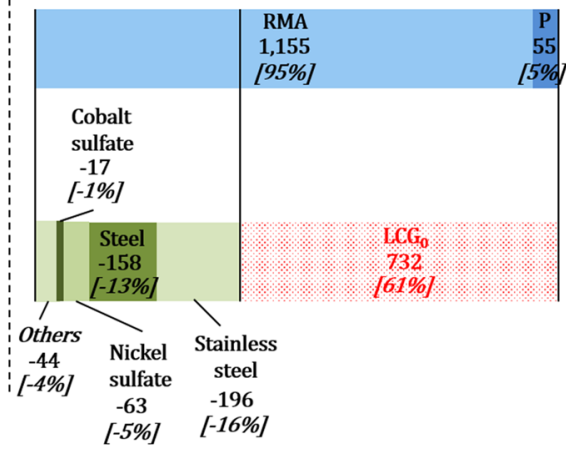

$\begin{array}{ll}\text { - RMA - raw material acquisition } & \text { LCG - life cycle gap } \\ \text { P-production } & \mathrm{X}_{0} \text { - product status quo } \\ \text { C - credits } & \end{array}$

(c)

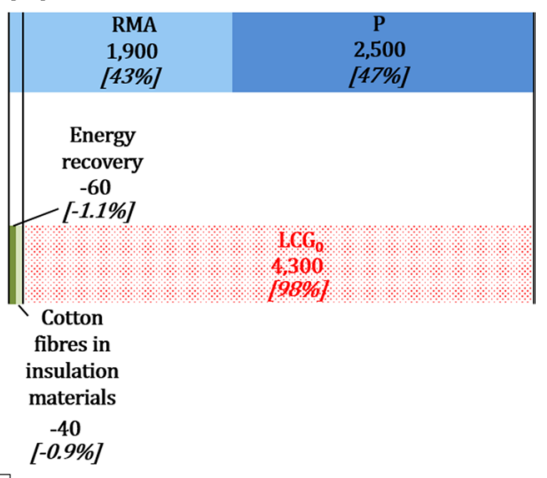

Fig. 2 LCG of the initial product systems in $\left(\mathrm{gCO}_{2} \mathrm{eq} / \mathrm{fU}\right)$ : a PET bottle, $\mathbf{b} \mathrm{Ni}-\mathrm{MH}$ battery, $\mathbf{c}$ T-shirt 
materials. At EoL, the main fraction of the T-shirt is incinerated (around 37\%) or deposited (around 52\%).

\section{Step 3: Identify Measures to Increase Circularity (Minimize} LCG of the Initial Product System). According to Step 3 of the methodology (see Fig. 1), different strategies to close products' material and energy cycles are identified in the literature and applied in this case study in order to reduce the existing LCG of the three representative products.

For the one-way PET bottle, an increased content of recycled PET materials within manufacturing is considered. Strict decontamination requirements are placed on recycled PET for food and beverage applications, including reprocessing with virgin resin with blending (multi-layered products) and a risk of colouration. Hence, a typical recycling content to be incorporated into a new PET bottle is around 35\% (Valentino 2017, according to Komly et al. 2012 and Shen et al. 2011). Much higher recycling rates of up to $>90 \%$ are likely to be reached by chemical recycling of PET materials, i.e. depolymerisation via hydrolase into monomers with virgin quality (Tournier, et al. 2020).

For the Ni-MH battery, an improvement of the recycling and upgrading process within the EoL phase is considered. The status quo includes recycling of the steel fractions (arising from the housing) and the nickel and cobalt elements (arising from the negative and positive electrodes) after mechanical pre-treatment and pyrometallurgical treatment of the battery. The newly developed recycling process also includes the recovery of cerium oxide and lanthanum oxide from the slag after pyrometallurgical treatment, using an additional acid leaching process and an ionometallurgical process (Salles et al. 2018). Such findings are in line with other approaches for the recovery of critical raw materials and precious metals from low-concentrated streams in hydrometallurgical technologies (Perez et al. 2019).

For the T-shirt, an improvement of the recycling and upgrading process within the EoL phase is likewise considered. In contrast to the status quo, where the main fraction of the T-shirt is incinerated (around 37\%) or deposited (around 52\%) (EC 2019), an advanced mechanical recycling process with sorting, washing, and shredding is introduced in order to substitute $80 \%$ of virgin cotton fibres in bales. The remaining $20 \%$ of losses are still incinerated (Schmidt et al. 2016). This is in line with other studies, which also state a mass loss rate of nearly $20 \%$ of the cotton fibres after the process of breaking fabrics for yarn recycling (Liu et al. 2020). Figure 3 illustrates the consideration of the recycled content approach for the PET bottle, and the consideration of the avoided burden approach for the Ni-MH battery and the T-shirt, according to Nordelöf et al. (2019).

Step 4: Assessing the LCG of the New Product System. A LCG computation can be used to assess the effects of the CE improvement measures derived from Step 3.

For the new one-way PET bottle (see Fig. 4a), which is now based on 35\% of recycled PET materials (bottle-tobottle), the increased content of recycled material allows the environmental impacts for the raw material acquisition of the PET bottle to be reduced by $14 \%$, and the LCG to be reduced in turn by $9 \%$, from the original $54 \%\left(6.3 \mathrm{gCO}_{2} \mathrm{eq}\right)$ to $45 \%\left(5.2 \mathrm{gCO}_{2} \mathrm{eq}\right)$ :

$$
\begin{aligned}
& \mathrm{LCG}_{\mathrm{NEW} ; \text { bottle }}=6.7 \mathrm{gCO}_{2} e q+3.3 \mathrm{gCO}_{2} \mathrm{eq} \\
& -4.8 \mathrm{gCO}_{2} \mathrm{eq}=5.2 \mathrm{gCO}_{2} \mathrm{eq}
\end{aligned}
$$

The environmental credits after recycling of the PET bottle in the second loop stay more or less constant and decrease only by about $0.5 \mathrm{gCO}_{2}$ eq (quality loss of $10 \%$ per recycling loop compared to virgin material).

For the Ni-MH battery (see Fig. 4b), the newly developed recycling solution for the additional recovery of cerium oxide and lanthanum oxide reduces the LCG by about $10 \%$, from the original $61 \%\left(732 \mathrm{gCO}_{2}\right.$ eq $)$ to $51 \%\left(620 \mathrm{gCO}_{2} \mathrm{eq}\right)$ :

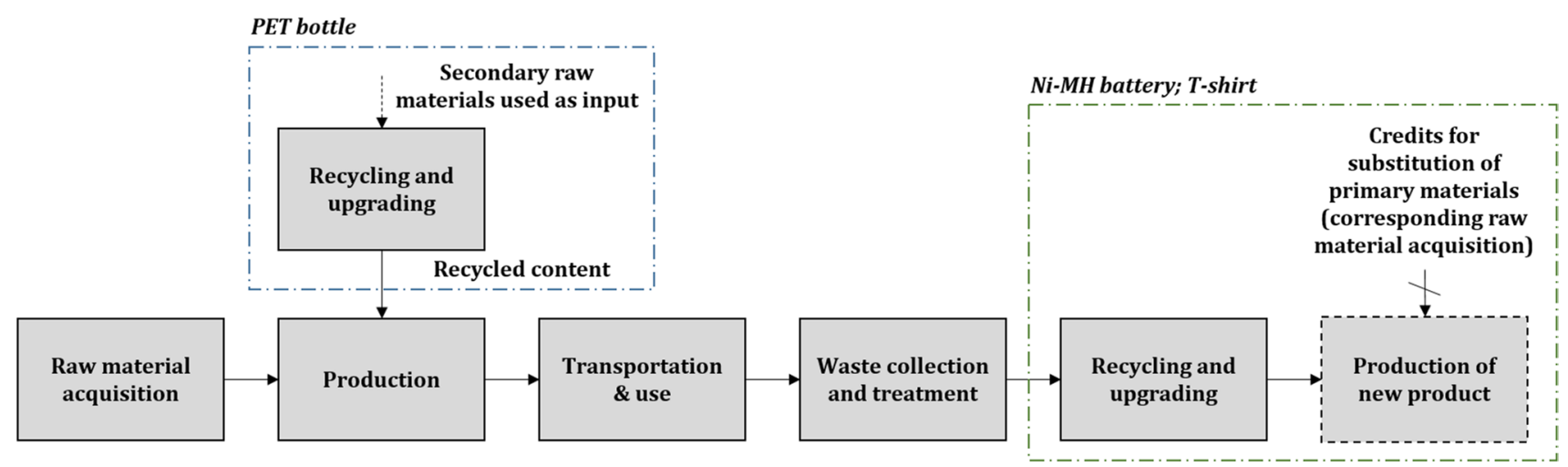

Fig. 3 Illustration of the measures to increase the circularity of the PET bottle, Ni-MH battery, and T-shirt. Diagramme modified according to (Nordelöf et al. 2019) 
Relative environmental impacts (\%) from a circular economy perspective

based on grams of carbon dioxide equivalents $\left(\mathrm{gCO}_{2} \mathrm{eq} /\right.$ functional unit)

(a)

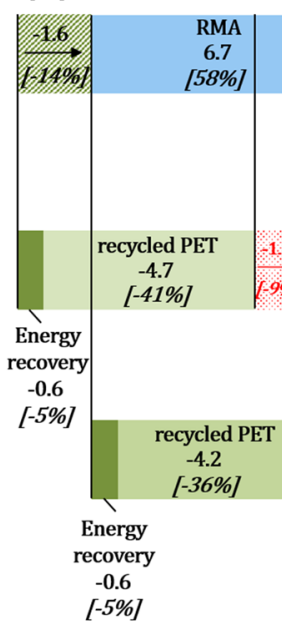

(b)

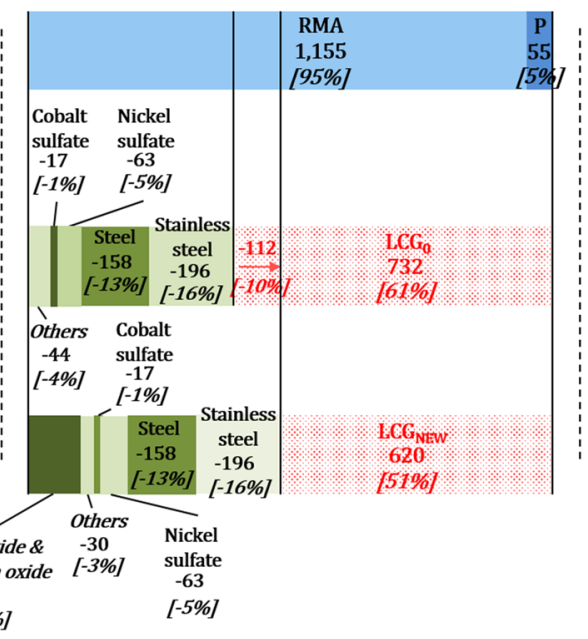

(c)

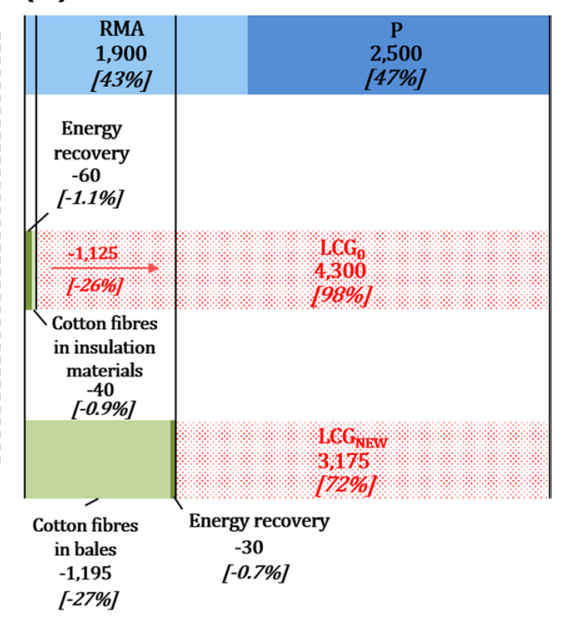

Fig. 4 LCG of the initial and new product systems in $\left(\mathrm{gCO}_{2} \mathrm{eq} / \mathrm{fU}\right)$ : a PET bottle, b Ni-MH battery, $\mathbf{c}$ T-shirt

$\mathrm{LCG}_{\mathrm{NEW} ; \text { battery }}=1,155 g \mathrm{CO}_{2} e q+55 g \mathrm{CO}_{2} e q-590 \mathrm{gCO}_{2} e q=620 \mathrm{gCO}_{2} e q$

Finally, for the T-shirt with improved material recycling of cotton fibres, the LCG is reduced by about $26 \%$, from $98 \%$ $\left(4,300 \mathrm{gCO}_{2} \mathrm{eq}\right)$ to $72 \%\left(3,175 \mathrm{gCO}_{2} \mathrm{eq}\right)$.

$\mathrm{LCG}_{\mathrm{NEW} \text { :shirt }}=1,900 \mathrm{gCO}_{2} \mathrm{eq}+2,500 \mathrm{gCO}$ eq $-1,225 \mathrm{gCO}_{2} \mathrm{eq}=3,175 \mathrm{gCO}_{2}$ eq

Figure 4 illustrates the LCG of both, the initial and the improved product systems.

Step 5 and Step 6: Assessing the LCA Results of the New Product System and Comparing with the Status Quo. After improvement of the LCG of each product system according to Step 3 (identification of potentials for improvement) and Step 4 (assessment of the new options for improvement), possible trade-offs for other life cycle stages have to be assessed (Step 5) and compared with the status quo (Step 6). Table 2 summarizes the LCA results of the new product system $\left(X_{N E W}\right)$, including a comparison with the initial product system $\left(X_{0}\right)$.

A comparison of the total results in Table 2 shows that in all three cases the overall life cycle impacts are lower for the new product systems. The defined restrictions within Step 6 were fulfilled (as indicated with a green tick), which means that the products' CE improvement ensures an effective contribution towards sustainable development (avoidance of negative trade-offs). In the case of the battery, the overall improvement is only marginal (3\%) due to higher recycling efforts, which counteract the benefits of more recycled material to some extent. The LCA results of the CE improved PET bottle show a decrease of manufacturing impacts by about $14 \%$, as $35 \%$ recycled PET material (bottle-to-bottle) is used. This leads to a small reduction in environmental credits at EoL by about $0.5 \mathrm{gCO}_{2} \mathrm{eq}$, as the quality factor of
Table 2 LCA results of the initial product system and the CE improved alternatives

\begin{tabular}{|c|c|c|c|c|c|c|}
\hline \multirow{2}{*}{ Life cycle phases } & \multicolumn{2}{|c|}{ One-way PET bottle } & \multicolumn{2}{|c|}{ Ni-MH battery } & \multicolumn{2}{|c|}{$T$-shirt } \\
\hline & $\mathrm{X}_{0}\left(\mathrm{gCO}_{2} e q\right)$ & $\mathrm{X}_{\mathrm{NEW}}\left(\mathrm{gCO}_{2} e q\right)$ & $\mathrm{X}_{0}\left(\mathrm{gCO}_{2} e q\right)$ & $\mathrm{X}_{\text {NEW }}\left(\mathrm{gCO}_{2} e q\right)$ & $\mathrm{X}_{0}\left(\mathrm{gCO}_{2} e q\right)$ & $X_{N E W}\left(g \mathrm{CO}_{2} e q\right)$ \\
\hline Raw material acquisition & 8.3 & 6.7 & 1,155 & 1,155 & 1,900 & 1,900 \\
\hline Production & 3.3 & 3.3 & 55 & 55 & 2,500 & 2,500 \\
\hline Use & 3.3 & 3.3 & 220 & 220 & 1,800 & 1,800 \\
\hline Recycling & 3.1 & 3.1 & 74 & 157 & 200 & 250 \\
\hline Credits & -5.3 & -4.8 & -478 & -590 & -100 & $-1,225$ \\
\hline Total & \begin{tabular}{|l|}
12.7 \\
\end{tabular} & 11.6 & 1,026 & 997 & 6,300 & 5,225 \\
\hline \multicolumn{7}{|c|}{ Difference "Total ${ }_{N E W} \leq$ Total $_{0} "$} \\
\hline $\mid$ absolute $\left(\mathrm{gCO}_{2} \mathrm{eq}\right)$ & \multicolumn{2}{|c|}{-1.1} & \multicolumn{2}{|c|}{-29.0} & \multicolumn{2}{|c|}{$-1,075$} \\
\hline relative (\%) & \multicolumn{2}{|c|}{$-9 \%$} & \multicolumn{2}{|c|}{$-3 \%$} & \multicolumn{2}{|c|}{$-17 \%$} \\
\hline
\end{tabular}


the recycled PET material (second loop) has to be reduced by about $10 \%$ compared to the first loop (virgin material).

At EoL of the Ni-MH battery, the increase of environmental credits by about $23 \%$ overcompensates the additional environmental impacts for recycling of the slag. The same situation occurs for the T-shirt: environmental credits increase by factor 12 and overcompensate the additional environmental impacts of recycling the textile cotton fibres.

\section{Discussion}

Our research shows that total life cycle impacts do not only result from the manufacturing and use phases, but also from EoL and closing products' material and energy cycles. To address this issue, we applied the life cycle gap analysis within the interpretation phase of the LCA for three entirely different products and identified substantial gaps of at least $54 \%$. Based on different findings and innovations for CE from literature, strategies to reduce these life cycle gaps were explored further:

- For one-way PET bottles, an increased content of recycled PET materials within manufacturing reduces the $\mathrm{LCG}$ by $9 \%$, from $54 \%\left(6.3 \mathrm{gCO}_{2}\right.$ eq $)$ to $45 \%$ (5.2 $\left.\mathrm{gCO}_{2} \mathrm{eq}\right)$.

- For Ni-MH batteries, an improvement of the slag recycling after mechanical pre-treatment and within pyrometallurgical treatment to recover cerium oxide and lanthanum oxide leads to LCG reductions of about $10 \%$, from $61 \%$ (732 $\mathrm{gCO}_{2}$ eq) to $51 \%\left(620 \mathrm{gCO}_{2}\right.$ eq).

- For T-shirts, advanced mechanical recycling (including sorting, washing, and shredding) is capable of substituting $80 \%$ of virgin cotton fibres in bales and leads to LCG reductions of $26 \%$, from $98 \%\left(4,300 \mathrm{gCO}_{2} \mathrm{eq}\right)$ to $72 \%$ $\left(3,175 \mathrm{gCO}_{2} \mathrm{eq}\right)$.

Moreover, in all three cases, negative trade-offs were avoided, as the total life cycle impacts were lower compared to the status quo (3\% reduction of total impacts for Ni-MH batteries, $9 \%$ for PET bottles, and 17\% for T-shirts). The contribution towards circular economy and sustainability is therefore positive.

The application of the life cycle gap analysis in this study demonstrates the usefulness of a LCGA as a supporting element within the interpretation phase of LCA studies. The LCGA enables the systematic evaluation of the environmental impacts of circularity options within the well-established and frequently used LCA method without demanding new impact assessment methods or modifications of the core methodology.

This pragmatic integration of circular economy thinking into LCA methodology bears a potential weakness. A
LCGA does not scrutinize the general necessity of a given product or service. Instead, it aims to increase its circularity and recyclability in given (linear) value chains and business models. The LCGA results for the three entirely different products not only show improvements in environmental performance and circularity, but also reveal large life cycle gaps even after considering ambitious options for improvement. Beyond LCGAs, disruptive innovations and new CEoriented business models might be better suited to achieve more comprehensive levels of circularity and sustainability, e.g., by preserving the function of products or services by sharing platforms and schemes promoting product redundancy and multifunctionality, or by preserving the product itself through lifetime increase with strategies such as durability, reuse, restore, refurbish, and remanufacture (Moraga et al. 2019).

\section{Conclusions and Outlook}

Many LCA studies, including the three different product examples considered in this paper, identify manufacturing and use phases as the main drivers of overall impact, and make significant efforts to analyze these phases accordingly. In contrast, the EoL phase is treated rather coarsely due to the fact that its processes, such as waste incineration, do not contribute significantly to overall impacts. Taking a CE perspective, the EoL phase holds enormous potential, though. Large portions of the efforts put into raw material acquisition and production could potentially be reclaimed by means of reuse, recycling, or other CE approaches. Developing CE strategies hence need a thorough investigation of the circularity potential of energy and material flows at the end of a product's life cycle. LCGA allows a transition of this mindset into LCA methodology by considering two novel principles within the interpretation stage:

1. Environmental credits in the EoL phase, stemming from the substitution of primary materials and energy, are uncoupled from the environmental impacts for recycling and not offset anymore, as it is done in classical crediting systems of common LCA studies.

2. The environmental credits are shifted to the manufacturing phase, as the focus of CE strategies is to close products material and energy flows and to minimize resource input and waste, emission, and energy leakages.

Using LCGA allows to shed light on the advantages of circular economy-oriented options within LCA interpretation, and on possible trade-offs with regard to life cycle thinking and sustainability. Further research is required to cover more complete sets of environmental impact categories and their trade-offs as well as other industries and 
product groups. The integration of cost assessments into LCGA is a further promising research strategy for the future (Dieterle and Viere 2021). This includes both the comparison of additional costs for and income from CE improvements for the manufacturer, and (macro-)economic assessments of the societal costs of CE strategies and their entire life cycle impacts. Integrated assessments of environmental impacts and economic aspects within LCGA might eventually also be used to identify barriers to and drivers of business models for circular and sustainable products.

The integration of circular decision-making and life cycle thinking is a vital challenge for industrial ecology and corporate sustainability research and application. Life cycle gap analyses provide an analytical contribution to this further development.

Acknowledgements The authors would like to appreciate the valuable contributions of the editors and the anonymous reviewers.

Author Contribution MD conceptualized and investigated the research finding, carried out the formal analysis and validation of the data, visualized the results, and wrote and edited the original draft. TV supervised, validated data, and was a major contributor in writing-reviewing and editing the manuscript. Both authors read and approved the final manuscript.

Funding Open Access funding enabled and organized by Projekt DEAL.

Data Availability The datasets used and/or analyzed during the current study are available in the references named in each section.

\section{Declarations}

Conflict of Interest The authors declare no competing interests.

Open Access This article is licensed under a Creative Commons Attribution 4.0 International License, which permits use, sharing, adaptation, distribution and reproduction in any medium or format, as long as you give appropriate credit to the original author(s) and the source, provide a link to the Creative Commons licence, and indicate if changes were made. The images or other third party material in this article are included in the article's Creative Commons licence, unless indicated otherwise in a credit line to the material. If material is not included in the article's Creative Commons licence and your intended use is not permitted by statutory regulation or exceeds the permitted use, you will need to obtain permission directly from the copyright holder. To view a copy of this licence, visit http://creativecommons.org/licenses/by/4.0/.

\section{References}

Ahbe S, Weihofen S, Wellge S (2018) The ecological scarcity method for the European Union - a Volkswagen research initiative: environmental assessments. Springer International Publishing AG, Heidelberg. https://doi.org/10.1007/978-3-658-19506-9

Dieterle M, Viere T (2021) Bridging product life cycle gaps in LCA \& LCC towards a circular economy. Procedia CIRP 98C:364-367. https://doi.org/10.1016/j.procir.2021.01.116
Dieterle M, Schäfer P, Viere T (2018) Life cycle gaps: interpreting LCA results with a circular economy mindset. Procedia CIRP 69:764-768. https://doi.org/10.1016/j.procir.2017.11.058

European Commission EC (2018a) Product environmental footprint category rules (PEFCRs) for high specific energy rechargeable for mobile applications. Version H, Brussels. https://ec.europa. eu/environment/eussd/smgp/pdf/PEFCR_Batteries.pdf

EC - European Commission (2018b) Product environmental footprint category rules (PEFCRs) for packed water. Version 1.0. Brussels. https://ec.europa.eu/environment/eussd/smgp/pdf/PEFCR_Packe dWater_FinalPEFCR_2018-04-23_V1.pdf

EC - European Commission. (2019). Product environmental footprint category rules (PEFCRs) for T-shirts. Version 1.0. Ambérieu-enBugey. https://ec.europa.eu/environment/eussd/smgp/pdf/PEFCR_ tshirt.pdf

Geissdoerfer M, Savaget P, Bocken N, Hultink E (2017) The circular economy - a new sustainability paradigm? J Clean Prod 143(1):757-768. https://doi.org/10.1016/j.jclepro.2016.12.048

Komlya C-E, Azzaro-Pantel C, Hubert A, Pibouleau L, Archambault V (2012) Multiobjective waste management optimization strategy coupling life cycle assessment and genetic algorithms: application to PET bottles. Resour Conserv Recycl 69:66-81. https://doi.org/ 10.1016/j.resconrec.2012.08.008

Liu Y, Huang H, Zhu L, Zhang C, Ren F (2020) Could the recycled yarns substitute for the virgin cotton yarns: a comparative LCA. Int J Life Cycle Assess 25:2050-2062. https://doi.org/10.1007/ s11367-020-01815-8

Moraga G, Huysveld S, Mathieux F, Blengini G, Alaerts L, Van Acker K, Dewulf J (2019) Circular economy indicators: what do they measure? Resources, Conservation \& Recycling 146:452-461. https://doi.org/10.1016/j.resconrec.2019.03.045

Nordelöf A, Poulikidou S, Chordia M, de Oliveira F, Tivander J, Arvidsson R (2019) Methodological approaches to end-of-life modelling in life cycle assessments of lithium-ion batteries. Batteries 5(3):51. https://doi.org/10.3390/batteries5030051

Perez J, Folens K, Leus K, Vanhaecke F, Van Der Voort P, Du Laing G (2019) Progress in hydrometallurgical technologies to recover critical raw materials and precious metals from low-concentrated streams. Resour Conserv Recycl 142:177-188. https://doi.org/10. 1016/j.resconrec.2018.11.029

Sala S, Cerutti A, Pant R (2018) Development of a weighting approach for the environmental footprint. Publications Office of the European Union, Luxembourg. https://doi.org/10.2760/945290

Salles A, Dieterle M, González M (2018) New recovery processes to produce rare earth - magnesium alloys of high performance and low cost. D5.3: LCA of REMAGHIC Process. European Union's Horizon 2020 research and innovation programme. Grant Agreement No 680629. http://www.remaghic-project.eu/remaghic_deliv erables

Schmidt A, Watson D, Roos S, Askham C, Poulsen P (2016) Gaining benefits from discarded textiles - LCA of different treatment pathways. Copenhagen: Nordic Council of Ministers 2016 (TemaNord 2016:537). https://doi.org/10.6027/TN2016-537

Shen L, Nieuwlaar E, Worrell E, Patel M (2011) Life cycle energy and GHG emissions of PET recycling: change-oriented effects. Int J Life Cycle Assess 16(6):522-536. https://doi.org/10.1007/ s11367-011-0296-4

Tournier V, Topham C, Gilles A, David B, Folgoas C, Moya-Leclai E, Marty A (2020) An engineered PET depolymerase to break down and recycle plastic bottles. Nature 580:216-219. https://doi.org/ 10.1038/s41586-020-2149-4

UN - United Nations General Assembly (2015) Transforming our world: the 2030 agenda for sustainable development. A/RES/70/1. United Nations. https://stg-wedocs.unep.org/bitstream/handle/20. 500.11822/11125/unepswiosm1inf7sdg.pdf?sequence $=1$ 
Valentino G (2017) Life Cycle Assessment of PET bottles: closed and open loop recycling in Denmark and Lombardy region. Politecnico Di Milano, Milan. https://www.politesi.polimi.it/bitstream/ 10589/136151/3/2017_10_Valentino.pdf

Zampori L, Pant R (2019) Product environmental footprint (PEF) method, EUR 29682 EN. Publications Office of the European Union, Luxembourg. https://doi.org/10.2760/265244,JRC115959
Publisher's Note Springer Nature remains neutral with regard to jurisdictional claims in published maps and institutional affiliations. 